\title{
Molecular detection of multidrug-resistant tuberculosis among smear-positive pulmonary tuberculosis patients in Jigjiga town, Ethiopia
}

This article was published in the following Dove Press journal:

Infection and Drug Resistance

9 March 2017

Number of times this article has been viewed

\author{
Mussie Brhane' \\ Ameha Kebede ${ }^{2}$ \\ Yohannes Petros ${ }^{2}$ \\ 'Department of Tuberculosis Culture \\ and DST Laboratory, Harar Health \\ Research and Regional Laboratory, \\ Harar, Ethiopia; ${ }^{2}$ Department of \\ Biology, College of Computational \\ and Natural Sciences, Haramaya \\ University, Haramaya, Ethiopia
}

Background: Molecular methods that target drug resistance mutations are suitable approaches for rapid drug susceptibility testing to detect multidrug-resistant tuberculosis (MDR-TB). The aim of the study was to determine MDR-TB cases and to analyze the frequency of gene mutations associated with rifampicin (RIF) and/or isoniazid (INH) resistance of Mycobacterium tuberculosis among smear-positive pulmonary tuberculosis patients.

Methods: Institution-based cross-sectional study design was employed. Sputum specimens were collected, and using a pretested questionnaire, data for associated risk factors for drug resistance were collected from 105 consecutive smear-positive pulmonary tuberculosis patients in Karamara General Hospital. Specimens were transported to Harar Health Research and Regional Laboratory, Harar, where molecular drug susceptibility testing was performed using GenoType ${ }^{\circledR}$ MTBDRplus assay.

Results: Of the total 105 sputum specimens, 98 (93.3\%) gave interpretable results, in which $67(68.4 \%)$ were new cases and $31(31.6 \%)$ were previously treated cases. Of these, $80(81.6 \%)$ were sensitive to both drugs and 18 (18.4\%) were resistant to RIF and/or INH. The prevalences of MDR-TB in total cases, new, and previously treated cases were $10(10.2 \%), 3(4.5 \%)$, and 7 (22.6\%), respectively. Among the ten total RIF-resistant specimens, eight (80\%) had resulted because of absence of $r p o B$ WT8 and presence of MUT3 and in all specimens, the amino acids changed were Ser531Lue. Of the 18 total INH-resistant specimens, 15 (83.3\%) had mutations in the kat G gene (katG MUT1, Ser315Thr1), indicating high-level resistance, while 3 (14.7\%) had mutations in the inhA promoter gene (Cys 15Thr), indicating low-level resistance.

Conclusion: Among the mutations associated with resistance to RIF and INH, the majority were in codon 531 of the rpoB gene and codon 315 of the $k a t G$ gene. Relatively high prevalence of MDR-TB was observed in the study.

Keywords: GenoType ${ }^{\circledR}$ MTBDRplus, isoniazid, multidrug-resistant tuberculosis, rifampicin, smear-positive pulmonary tuberculosis

\section{Background}

Tuberculosis (TB) is a chronic infectious disease caused by Mycobacterium tuberculosis complex (MTBC), with a majority of the cases caused by $M$. tuberculosis (MTB). ${ }^{1}$ With an estimated 8.6 million new cases of TB $(13 \%$ coinfected with human immunodeficiency virus) and 1.3 million deaths in 2012, TB remains a major cause of morbidity and mortality worldwide. ${ }^{2}$ Ethiopia is one of the 22 high-burden TB countries. $^{3}$ Drug-resistant TB (DR-TB), including multidrug-resistant TB (MDR-TB, that is resistant to at least isoniazid [INH] and rifampicin [RIF], the two most important first-line anti-TB drugs), has emerged as a serious threat to global health. ${ }^{4}$ In 2012 ,
Correspondence: Mussie Brhane

Tuberculosis Culture and DST Laboratory, Harar Health Research and Regional Laboratory, PO Box: 819, Harar, Harar Regional State, Ethiopia

Tel +25125913427484

Email musbr1836@gmail.com 
$3.6 \%$ of newly diagnosed and $20 \%$ of previously treated cases were estimated to have MDR-TB globally, with noticeable geographic variations in prevalence. ${ }^{2}$ Based on the second round drug resistance survey performed in Ethiopia (2011-2013), MDR-TB prevalence was reported as $2.8 \%$ in new and $18.6 \%$ in previously treated TB patients. ${ }^{5}$

Drug resistance develops due to random genetic mutations in particular genes responsible for resistance in MTB strains, usually because of inappropriate treatment of patients. ${ }^{6}$ Accurate and rapid detection of TB, including DR-TB, is critical for improving patient outcomes and decreasing TB transmission. ${ }^{7}$ The effectiveness of a standard anti-TB treatment regimen correlates well with the in vitro drug susceptibility pattern of the infecting tubercle bacilli. The results of drug susceptibility testing (DST) help select a proper treatment regimen or modify the treatment regimen for a better management of patients and for surveillance and timely control of the spread of DR-TB in the community. ${ }^{8}$ For proper treatment and control of TB, the World Health Organization (WHO) has recommended countries to expand their capacity for culture-based DST and consider new, molecular-based assays for diagnosing drug resistance. ${ }^{9}$

Molecular methods that target drug resistance mutations are a suitable approach for a rapid DST. ${ }^{3}$ Rapid tests can provide results within days (even without culture, ie, directly on specimens), and thus enable prompt and appropriate treatment, decrease morbidity and mortality, and control transmission. ${ }^{10}$ In 2008, WHO recommended the use of molecular line probe assays (LPAs) for the diagnosis of MDR-TB. ${ }^{9}$ The GenoType ${ }^{\circledR}$ MTBDRplus (Hain Lifescience $\mathrm{GmbH}$, Nehren, Germany) assay is a commercial LPA developed for the detection of INH and RIF resistance in MTB isolates and smear-positive specimens. This assay is a DNA strip assay, which uses polymerase chain reaction (PCR) and reverse hybridization, that detects the most common mutations found in the rpoB, katG, and inhA genes. ${ }^{8}$ The mutations that predominate in RIF-resistant MTB strain are located in an 81 bp "core region" of the rpoB gene (95\% of all RIF-resistant strains). ${ }^{11}$ Resistance to INH is conferred by mutations in catalase peroxidase enzyme gene, $k a t G$, and in the $i n h A$ regulatory region. ${ }^{12,13}$ Mutations in $k a t G$ gene and inh $A$ gene were related to high- and low-level INH resistance, respectively. ${ }^{14}$

Ethiopia is working toward controlling the emergence and spread of drug resistance in the general population. ${ }^{3}$ The eastern part of Ethiopia is known for its high TB case load, and anti-TB drugs have been in use for a long time in the area before the implementation of Direct Observed Treatment
Short course (DOTS) ${ }^{15}$ The prevalence of drug-resistant TB in Somali region of Ethiopia, in general, and Jigjiga area, in particular, is not well documented. So far, there is no report of the prevalence of MDR-TB among new and previously treated cases in the study area. The diagnosis of drug-resistant TB is made only by laboratories performing DST. Indeed, the LPAs test may be used to improve the management of TB and MDR-TB incidence in the study area as in most of the industrialized countries. ${ }^{16}$ Thus, the aim of the study was to determine the drug resistance pattern, including MDR-TB cases, and to analyze the frequency of gene mutations associated with RIF and/or INH resistance of MTB among smearpositive pulmonary tuberculosis (PTB) patients attending Karamara General Hospital in Jigjiga town.

\section{Materials and methods Study design and area}

In this study, institution-based cross-sectional study design was employed. This study was conducted in a health institution in which data for associated risk factors for drug resistance were collected using a pretested questionnaire and sputum specimens were collected from smear-positive PTB patients for molecular detection of drug-resistant MTB during the study period. The study was conducted at Karamara General Hospital, which is the only public hospital located in Jigjiga town and the main center for TB diagnosis and treatment in the region.

\section{Eligibility criteria}

In general, smear-positive PTB patients and new and/or previously treated cases who gave consent to participate were eligible to be included in the study. Seriously ill individuals, individuals who were $<18$ years of age, Extra-PTB and new patients who had already started TB treatment were excluded from the study. Likewise, previously treated patients, who had already started retreatment regimens, were also excluded from the study.

\section{Sample size determination and sampling techniques}

The required sample size was determined by using single population formula and considering the expected proportion of RIF resistance $(6 \%),{ }^{17}$ desired precision of $5 \%$ at $95 \%$ confidence interval, and expected losses of $20 \%$. Thus, the final sample size of the study was 105 smear-positive PTB patients. The study subjects were identified by using consecutive sampling until the required sample size was reached. 


\section{Sample collection and processing}

In this study, about $5 \mathrm{~mL}$ of sputum sample from each of the 105 consecutive AFB smear-positive PTB patients was collected in $50 \mathrm{~mL}$ sterile, plastic, screw-capped centrifuge tubes and transported to Harar Health Research and Regional Laboratory in Harar town using a triple package transport system for further analysis. The sputum specimens were then handled in class II biosafety cabinet in a biosafety level-2 laboratory. Sputum specimens were decontaminated by $\mathrm{N}$-acetyl-L-cysteine sodium hydroxide method with a final concentration of $1 \%$. Then, the decontaminated samples were used for detection of gene mutations associated with RIF and INH resistance using the GenoType ${ }^{\circledR}$ MTBDRplus assay method (Hain Lifescience $\mathrm{GmbH}$ ). A direct smear was performed from the sediment, stained by $\mathrm{ZN}$ staining, and scored according to the bacillary load as described by the national guideline. ${ }^{3}$ Also, $0.5 \mathrm{~mL}$ of the processed sample was used for DNA isolation in a screw-capped tube. ${ }^{18,19}$

\section{GenoTypeMTBDRplus DST}

The molecular assay method used for detection of RIF- and INH-resistant mutations and identification was performed using GenoType ${ }^{\circledR}$ MTBDRplus assay version 2.0 (Hain Lifescience $\mathrm{GmbH}$ ) according to the manufacturer's instructions. The assay was a rapid and accurate test to identify cases with MDR-TB. ${ }^{3}$ Using multiplex PCR, the genes responsible for drug resistance, such as $k a t G$, inh $A$, and $r p o B$, were amplified and the resulting biotin-labeled amplicons were hybridized to DNA probes bound to membrane on the strip. This was followed by addition of a conjugate and substrate to detect visible band patterns on the strip, which was performed manually using a shaker water bath at $45^{\circ} \mathrm{C}$. Then, the strips were allowed to dry and interpreted according to the manufacturer's recommendation. ${ }^{18,19}$

For each gene, the assay was done to test for the presence of wild-type (WT) and mutant (MUT) probes. Each strip of the assay had 27 reaction zones, including six controls (conjugate, amplification, MTBC, rpoB, katG, and inhA controls), eight rрoB WT (WT-1 to WT-8) and four MUT (rpoB MUT Asp516Val, rpoB MUT His5267yr, rpoB MUT His526Asp, and rpoB MUT Ser531Leu) probes, one katG WT (WT-315) and two MUT probes (katG MUT Ser315Thr1 and $k a t G$ MUT Ser315Thr2), and two inhA WT (WT-15/-16 and WT-8) and four MUT probes (inhA MUT1 Cys15Thr, inhA MUT2 Ala16Gly, inhA MUT3A Thr8Cys, and inhA MUT3B Thr8Ala). This assay included three steps: DNA extraction, multiplex PCR amplification, and reverse hybridization. These steps were carried out in three separate rooms of the facility with restricted access and unidirectional workflow. ${ }^{18}$

\section{Quality control}

All procedures were carried out using standard operating procedures. Based on the assay's manufacturer recommendation, for each batch of specimens in which LPA was performed, an "extraction positive control" (ATCC MTB strain $\mathrm{H}_{37} \mathrm{Rv}$ which was susceptible to all standard anti-TB drugs,), an "extraction negative control" (molecular grade water), and a "PCR master mix negative control" were used as quality control. When any of the quality controls failed, the assay was repeated starting from DNA extraction.

\section{Data processing and analysis}

In this study, primary data were collected from the assay using standard formats recommended by the manufacturer. The investigator checked, sorted, and reviewed the data manually for errors and inconsistencies. Data entry and analysis was performed using SPSS version 16 statistical software (SPSS Inc., Chicago, IL, USA). A bivariate logistic regression analysis was done to select the variables to be entered into the final logistic multivariable analysis. Explanatory variables $(P<0.25)$ were entered into the final logistic regression (multivariate) model, based on the likelihood ratio. The multivariate logistic regression model was constructed using forward method. Associations between the independent variables and the outcome variable were assessed using adjusted odds ratio (AOR) and $95 \%$ confidence interval for the AOR, and $P$-values $<0.05$ were used as the cutoff point for statistical significance.

\section{Ethical clearance}

Ethical clearance was obtained from Haramaya University Postgraduate Program Directorate Ethical Review Committee. Permission was also obtained from the Somali Regional Health Bureau and from Harar Regional Laboratory. Informed oral consent was obtained from the study participants. Confidentiality of the participants was kept by the investigator.

\section{Results}

\section{Characteristics of the study participants}

In this study, of the total 105 study participants' specimens, $98(93.3 \%)$ gave interpretable results. The rest were excluded because DNA of MTBC was not detected in the specimens using GenoTypeMTBDRplus assay. A majority of the patients, $58(59.2 \%)$, were males and $40(40.8 \%)$ were females (Table 1). The mean and median age was 35 and 33 years, respectively. Of the total, 67 (68.4\%) were new smear-positive PTB patients and 31 (31.6\%) were previously 
Table I Distribution of the study participants $(\mathrm{N}=98)$ by sociodemographic characteristics, lifestyle and HIV status vis-à-vis their previous history of treatment

\begin{tabular}{|c|c|c|c|}
\hline Variables & $\begin{array}{l}\text { New cases }(n=67) \text {, } \\
\text { F (\%) }\end{array}$ & $\begin{array}{l}\text { Previously treated cases } \\
(n=31), F(\%)\end{array}$ & $\begin{array}{l}\text { Total }(\mathbf{N}=98) \text {, } \\
\mathbf{F}(\% *)\end{array}$ \\
\hline \multicolumn{4}{|l|}{ Sex } \\
\hline Female & $30(44.8)$ & $10(32.3)$ & $40(40.8)$ \\
\hline Male & $37(52.2)$ & $21(67.7)$ & $58(59.2)$ \\
\hline \multicolumn{4}{|l|}{ Age (years) } \\
\hline $18-30$ & $30(44.8)$ & $12(38.7)$ & $42(42.9)$ \\
\hline $31-50$ & $31(46.2)$ & $13(4 \mid .9)$ & 44 (44.9) \\
\hline$>50$ & $6(9)$ & $6(19.4)$ & $12(12.2)$ \\
\hline Mean (SD) & & & $35(12.53)$ \\
\hline \multicolumn{4}{|l|}{ Educational status } \\
\hline Illiterate & $26(38.8)$ & $13(4 \mid .9)$ & $39(39.8)$ \\
\hline Read and write & $35(52.2)$ & $14(45.2)$ & $49(50)$ \\
\hline College and above & $6(9)$ & $4(12.9)$ & $10(10.2)$ \\
\hline \multicolumn{4}{|l|}{ Residence } \\
\hline Rural areas & $18(26.9)$ & $10(32.3)$ & $28(28.6)$ \\
\hline Urban & $49(73.1)$ & $21(67.7)$ & $70(71.4)$ \\
\hline \multicolumn{4}{|c|}{ Degree of smear positivity } \\
\hline Scanty & $7(10.4)$ & - & $7(7.1)$ \\
\hline+1 & $33(49.3)$ & $18(58.1)$ & $51(52.1)$ \\
\hline+2 & $16(23.9)$ & $7(22.6)$ & $23(23.5)$ \\
\hline+3 & II (16.4) & $6(19.3)$ & $17(17.3)$ \\
\hline \multicolumn{4}{|l|}{ HIV status } \\
\hline Nonreactive & $64(95.5)$ & $26(83.9)$ & $90(91.8)$ \\
\hline Reactive & $3(4.5)$ & $5(16.1)$ & $8(8.2)$ \\
\hline \multicolumn{4}{|c|}{ Family history of TB patients } \\
\hline No & $57(85.1)$ & $21(67.7)$ & $78(79.6)$ \\
\hline Yes & $10(14.9)$ & $10(32.3)$ & $20(20.4)$ \\
\hline \multicolumn{4}{|c|}{ Close contact to TB patients } \\
\hline No & $58(86.6)$ & $26(83.9)$ & $84(85.7)$ \\
\hline Yes & $9(13.4)$ & $5(16.1)$ & $14(14.3)$ \\
\hline \multicolumn{4}{|l|}{ Alcohol usage } \\
\hline No & $62(92.5)$ & $31(100)$ & $93(94.9)$ \\
\hline Yes & $5(7.5)$ & - & $5(5.1)$ \\
\hline \multicolumn{4}{|l|}{ Smoking status } \\
\hline No & $58(86.6)$ & $26(83.9)$ & $84(85.7)$ \\
\hline Yes & $9(13.4)$ & $5(16.1)$ & $14(14.3)$ \\
\hline
\end{tabular}

Notes: \%, (F/N) 100; \%*, (F/n) 100.

Abbreviations: $F$, frequency; HIV, human immunodeficiency virus; SD, standard deviation; TB, tuberculosis.

treated smear-positive patients. The study participants' sociodemographic characteristics, lifestyle, and medical history are presented in Table 1.

\section{RIF and/or INH resistance pattern}

Overall, of the valid results obtained from 98 samples, 80 $(81.6 \%)$ were sensitive to both drugs, $18(18.4 \%)$ were resistant to RIF and/or INH, and 10 (10.2\%) were MDR-TB cases. In this study, among the total 67 new cases observed, 3 (4.5\%) showed MDR-TB. On the other hand, of the total 31 cases previously treated, 7 (22.6\%) were MDR-TB cases. The prevalence of any resistance to RIF and INH was 10 $(10.2 \%)$ and $18(18.4 \%)$, respectively (Table 2 ). While there was no monoresistance to RIF, monoresistance to INH was 8 (8.2\%): 5 (7.5\%) among new cases and 3 (9.7\%) among previously treated cases.

\section{Association between risk factors and drug resistance patterns}

In the present study, multivariate logistic regression (Table 3) analysis was performed to determine the association between risk factors and any drug resistance among the study participants. On the basis of the outcomes of bivariate analysis, the risk factors (independent variables), age, educational status, and alcohol usage, were excluded from the final (multivariate) regression analysis $(P \geq 0.25)$. Therefore, 
Table 2 GenoType ${ }^{\circledR}$ MTBDRplus assay results among new and previously treated cases in Karamara General Hospital, Jigjiga town

\begin{tabular}{|c|c|c|c|}
\hline Resistant status & $\begin{array}{l}\text { New cases }(n=67), \\
\text { F }(\%)\end{array}$ & $\begin{array}{l}\text { Previously treated } \\
\text { cases }(n=31), F(\%)\end{array}$ & $\begin{array}{l}\text { Total }(\mathbf{N}=98) \text {, } \\
\text { F (\%*) }\end{array}$ \\
\hline Susceptible & $59(88.1)$ & $21(67.7)$ & $80(81.6)$ \\
\hline Any resistance & $8(11.9)$ & $10(32.3)$ & $18(18.4)$ \\
\hline RIF & $3(4.5)$ & $7(22.6)$ & $10(10.2)$ \\
\hline $\mathrm{INH}$ & 8 (II.9) & $10(32.3)$ & $18(18.4)$ \\
\hline \multicolumn{4}{|l|}{ Monoresistance } \\
\hline RIF & 0 & 0 & 0 \\
\hline $\mathrm{INH}$ & $5(7.5)$ & $3(9.7)$ & $8(8.2)$ \\
\hline Multidrug resistance & $3(4.5)$ & $7(22.6)$ & $10(10.2)$ \\
\hline
\end{tabular}

Notes: \%, (F/N) 100; \%*, (F/n) 100.

Abbreviations: $\mathrm{F}$, frequency; INH, isoniazid; RIF, rifampicin.

Table 3 Bivariate and multivariate analyses for selected characteristics of the study participants and their association with any resistance to rifampicin and/or isoniazid based on GenoType ${ }^{\circledR}$ MTBDRplus assay

\begin{tabular}{|c|c|c|c|c|c|}
\hline Variables & Any drug resistance (\%) & COR $(95 \% \mathrm{Cl})$ & $P$-value & AOR $(95 \% \mathrm{CI})$ & $P$-value \\
\hline \multicolumn{6}{|l|}{ Sex } \\
\hline Female & $5 / 40(12.5)$ & $\mathrm{R}$ & 0.219 & $\mathrm{R}$ & 0.707 \\
\hline Male & 13/58 (22.4) & $2.02(0.66-6.21)$ & & $1.36(0.27-6.85)$ & \\
\hline \multicolumn{6}{|c|}{ Degree of S+ } \\
\hline Scanty & $\mathrm{I} / 7(14.3)$ & $\mathrm{R}$ & & $\mathrm{R}$ & \\
\hline+1 & $|1 / 5|(21.6)$ & $2.67(0.14-49.76)$ & 0.511 & $5.06(0.09-227.72)$ & 0.427 \\
\hline+2 & $5 / 23(21.7)$ & $4.4(0.52-36.94)$ & 0.172 & $3.02(028-32.62)$ & 0.362 \\
\hline+3 & $\mathrm{I} / \mathrm{I} 7(5.9)$ & $4.44(0.47-42.18)$ & 0.194 & $10.82(0.88-133.87)$ & 0.630 \\
\hline \multicolumn{6}{|l|}{ Residence } \\
\hline Rural & $8 / 28(28.6)$ & $\mathrm{R}$ & 0.105 & $\mathrm{R}$ & 0.090 \\
\hline Urban & $10 / 70(14.3)$ & $0.42(0.15-1.20)$ & & $0.30(0.08-1.21)$ & \\
\hline \multicolumn{6}{|l|}{ HIV status } \\
\hline No & $15 / 90(16.7)$ & $\mathrm{R}$ & 0.161 & $\mathrm{R}$ & 0.626 \\
\hline Yes & $3 / 8(37.5)$ & $3.00(0.65-13.92)$ & & $1.87(0.15-23.33)$ & \\
\hline \multicolumn{6}{|c|}{ Previous Rx history of TB } \\
\hline No & $8 / 67(11.9)$ & $\mathrm{R}$ & 0.005 & $\mathrm{R}$ & $0.017 *$ \\
\hline Yes & $10 / 31(32.3)$ & $4.7 \mid(1.61-13.80)$ & & $6.86(1.41-33.32)$ & \\
\hline \multicolumn{6}{|c|}{ Family history of TB } \\
\hline No & $9 / 78(10.3)$ & $\mathrm{R}$ & 0.008 & $\mathrm{R}$ & 0.212 \\
\hline Yes & $9 / 20(45)$ & $4.53(1.49-13.8 I)$ & & $2.79(0.56-14.04)$ & \\
\hline \multicolumn{6}{|c|}{ Close contact with TB pts } \\
\hline No & $8 / 84(9.5)$ & $\mathrm{R}$ & 0.000 & $\mathrm{R}$ & $0.006 *$ \\
\hline Yes & $10 / 14(71.4)$ & $9.87(2.83-34.36)$ & & $|2.4|(2.06-74.86)$ & \\
\hline \multicolumn{6}{|c|}{ Smoking status } \\
\hline No & I3/84 (I5.5) & $\mathrm{R}$ & 0.002 & $\mathrm{R}$ & $0.045 *$ \\
\hline Yes & $7 / 14(50)$ & $6.64(1.95-22.58)$ & & $9.66(1.06-83.30)$ & \\
\hline
\end{tabular}

Note: *Significant $(P<0.05)$. $P$-values written in bold were aimed to show significant variables (their $P$-value is less than 0.05$)$ among the risk-factors

Abbreviations: AOR, adjusted odds ratio; $\mathrm{Cl}$, confidence interval; COR, crude odds ratio; HIV, human immunodeficiency virus; pts, patients; $\mathrm{R}$, reference value; $\mathrm{Rx}$, treatment; S+, smear positive; TB, tuberculosis.

previous treatment history of TB $(P=0.017)$, close contact with TB patients $(P=0.006)$, and smoking cigarette $(P=0.045)$ were significantly associated with the development of any drug resistance.

\section{Frequency of gene mutations among drug-resistant specimens}

Results of the molecular method DST showed that 18 of the specimens had mutations conferring resistance to both
RIF and INH or INH only (Table 4). Mutations conferring resistance to both INH and RIF were detected in 18 and 10 of the specimens, respectively. MTB obtained from ten of the samples showed mutations in both $r p o B$ gene and kat $G$ gene or inhA promoter region, indicating that they were MDR. Among the total ten RIF-resistant MTB, the distribution of mutant genes in various regions showed that eight were because of the absence of $r p o B$ WT8 and presence of rpoB MUT3 and the amino acids changed were Ser531Lue. 
Table 4 Determination of frequency of gene mutations associated with resistance to isoniazid and rifampicin by GenoType ${ }^{\circledR M T B D R p l u s}$ assay

\begin{tabular}{|c|c|c|c|c|}
\hline Anti-TB drug & $\begin{array}{l}\text { Number of resistant } \\
\text { specimens }\end{array}$ & Patterns of gene mutations (WT/MUT) & Amino acid changes & $F(\%)$ \\
\hline \multirow[t]{2}{*}{ Isoniazid } & 18 & $\Delta k a t G$ WT/katG MUTI & Ser3/5Thrl & $15(83.3)$ \\
\hline & & $\triangle$ inhA WTI/inhA MUTI & Cys/5Thr & $3(16.7)$ \\
\hline \multirow[t]{3}{*}{ Rifampicin } & 10 & $\Delta r p o B$ WT8/rpoB MUT3 & Ser53ILeu & $8(80)$ \\
\hline & & $\Delta r p o B$ WT7/rpoB MUT2A & His526Tyr & $I(10)$ \\
\hline & & $\Delta r p o B$ WT7/rpoB MUT2B & His526Asp & $\mathrm{I}(\mathrm{I0})$ \\
\hline
\end{tabular}

Abbreviations: $\Delta$, deletion; F, frequency; MUT, mutant; TB, tuberculosis; WT, wild-type; (WT/MUT), deletion of wild-type and presence of mutant.

Whereas the remaining were: one was due to the absence of rpoB WT7 and presence of rpoB MUT2B, with an amino acid change of His526Asp, and another one was due to deletion in $r p o B$ WT7/rpoB MUT2A, with a change in amino acids His526Tyr (Table 4). All mutations in the rpoB gene, which indicated RIF resistance, also had mutation in either $\mathrm{kat} G$ gene or inhA promoter region that showed INH resistance.

Mutations associated with INH resistance were more often encountered, as compared to those seen in RIF resistance specimens. Of the total 18 INH-resistant specimens, 15 had mutations in the codon 315 of $k a t G$ ( $k a t G \mathrm{WT} / \mathrm{kat} G$ MUT1) gene, with a change in amino acids Ser315Thr1, indicating high-level resistance, while 3 of the specimens had mutation in the codon 15 of inhA promoter gene (inhA WT1/inhA MUT1), with a change in amino acids Cys $15 T h r$, indicating low-level resistance. There was no specimen that showed mutations at both $k a t G$ and $\operatorname{inh} A$ genes. All kat $G$ gene mutations were as a result of the absence of WT probes and the presence of mutant probes, as was the case with the inh $A$ gene mutations (Table 4).

\section{Discussion}

Rapid identification of drug resistance, particularly MDR-TB, is most important to help reduce the spread of disease. ${ }^{9}$ The MTBDRplus assay has been widely used in clinical routines for identification of MTB complex and detection of RIF and INH resistance. The purpose of the study was to identify DR-TB including MDR-TB and to determine the frequency of mutations conferring resistance to RIF and INH in clinical specimens in the study area.

In the present study, the overall prevalence of MDR-TB cases was $10.2 \%$. According to the review paper by Biadglegne et al, ${ }^{20}$ the proportion of MDR-TB cases varies from place to place in Ethiopia. The finding from the present study is comparable to the studies conducted by Hussein et $\mathrm{al}^{21}$ However, the studies conducted by Agonafir et $\mathrm{al}^{22}$ and Abate et $\mathrm{al}^{23}$ reported significantly higher rate of MDR-TB cases. On the other hand, studies conducted in other parts of the country reported lower prevalence of MDR-TB cases..$^{20,24}$
In the present study, the prevalence of MDR-TB among new and previously treated cases was $4.5 \%$ and $22.6 \%$, respectively. This is a higher rate compared to the second round drug resistance survey performed in Ethiopia from 2011 to 2013, where MDR-TB prevalence was shown to be $2.8 \%$ and $18.6 \%$ among new and previously treated TB patients, respectively. ${ }^{5}$ Similarly, this study has also revealed higher prevalence of MDR-TB than the global MDR-TB incidence reported by WHO, in which $3.6 \%$ of newly diagnosed and $20 \%$ of retreatment cases were estimated to have MDR-TB. ${ }^{2}$

Among new patients, $4.5 \%$ were MDR-TB cases (Table 2). This result was higher than those reported from previous studies conducted in Ethiopia which showed values ranging from $0.9 \%$ to $2.3 \%{ }^{22,24-26}$ and other studies conducted in African countries such as Kenya $(0.54 \%),{ }^{27}$ Madagascar $(0.2 \%),{ }^{28}$ and Tanzania $(0.4 \%) .{ }^{29}$ Studies conducted in other parts of the world also reported low rates of MDR-TB among new cases. ${ }^{30,31}$ However, a higher rate of MDR-TB in new cases was observed in other studies: $7.7 \%$ in Swaziland, ${ }^{32}$ $5.8 \%$ in Mozambique, ${ }^{33}$ and $5.2 \%$ in Somalia. ${ }^{34}$ This indicates that there was high transmission of drug resistance in the community.

Similarly, in the present study, MDR-TB was observed to be higher $(22.6 \%)$ among previously treated cases than in studies conducted in eastern Amhara region of Ethiopia $(18.5 \%),{ }^{24}$ Kenya $(8.5 \%),{ }^{27}$ Madagascar $(3.4 \%),{ }^{28}$ and Uganda $(12.7 \%) .{ }^{35}$ But in this study, MDR-TB was lower than that reported by $A$ bate et $\mathrm{al}^{23}(46.3 \%)$. In studies conducted by Liu et $\mathrm{al}^{36}$ in northeastern China and Choi et $\mathrm{al}^{37}$ in Korea, the prevalence of MDR-TB was greater than that found in the present study among previously treated cases. In this study, there was a higher proportion of MDR-TB than that reported from other parts of Ethiopia previously. This may possibly be due to ineffective functioning of TB control programs in the study area, which included irregular supply of anti-TB drugs, less-organized patient diagnosis, treatment, and follow-up, and improper patient adherence to treatment, which might have contributed to the high prevalence of MDR-TB cases in the study area. 
In the present study, it was observed that drug resistance was significantly associated $(P<0.05)$ with previous history of TB treatment (Table 3). In agreement with this finding, previous studies in Ethiopia reported that previous history of treatment was the most significant risk factor for drug resistance..$^{22-24,38,39}$ Similar reports were also documented in studies conducted in East Africa, India, and China. ${ }^{37,40}$ The association of previous history of treatment with anti-TB to DR-TB in this study might be explained by inadequate or irregular drug supply, inappropriate chemotherapy regimens, and lack of supervision of treatment in hospitals. Compared to other studies, in the present study, close contact with TB patients and smoking cigarette were also significantly associated with the development of drug resistance.

RIF resistance is often considered as a surrogate marker for checking MDR-TB. ${ }^{41,42}$ This hypothesis is supported by the finding in the present study that $100 \%$ of the RIFresistant specimens were MDR (Table 2). In this study, 10 (10.4\%) rров gene mutations that indicated RIF resistance were detected. Previous studies reported that $95 \%$ of RIFresistant MTB worldwide have mutations within the $81 \mathrm{bp}$ core region of the rpoB gene, mainly in the region of codon $507-533 . .^{11,14,43}$ In the present study, mutations in this region were detected in $100 \%$ of RIF-resistant specimens. Of the total $r p o B$ gene mutations detected, the most frequently mutated codon in the study was codon $531(80 \%)$ at position Ser531Leu, which is similar to that reported in previous studies. ${ }^{17,44,45}$ The remaining $20 \%$ of the mutations were at the position of codon 526 (an amino acid change of His526Asp and His5267yr).

In this study, the percentage of gene mutation at position Ser531Leu (80\%) was higher than that reported by Tessema et al, ${ }^{17}$ which was $73 \%$ at that position, whereas a study conducted in western Poland detected slightly higher proportion $(82.7 \%) .{ }^{44}$ In the present study, it was observed that there was no mutation detected at the WT probes alone, that is, all mutations at the WT were also detected at the MUT probes. This is different from the previously reported gene mutation distribution, in which $60 \%$ and $20 \%$ of the mutations were only detected at the WT probes by Zhang et al ${ }^{46}$ and Tessema et al,${ }^{17}$ respectively. This reflects the difference in the distribution of gene mutations associated with RIF resistance in different geographic locations.

Previous studies have already indicated that INH resistance was mediated by mutations in several genes, most commonly $k a t G$, particularly in codon 315 , and the promoter region of inhA gene. ${ }^{11,13}$ Many researchers have also shown that $40 \%-95 \%$ of INH resistance may be defined as high-level drug resistance due to the $k a t G$ gene mutations, while $8 \%-43 \%$ of INH resistance may be defined as lowlevel drug resistance mainly caused by mutations in the promoter region of inhA gene. ${ }^{11,13,14}$ In the present study, $83.3 \%$ of INH resistance was attributed to $k a t G$ mutations, which conferred high-level resistance to $\mathrm{INH}$, in addition to a low-level drug resistance observed in $16.7 \%$ of INH-resistant cases (Table 4), which were within the ranges reported by previous studies.

Furthermore, several studies have also shown that $75 \%-90 \%$ of the $k a t G$ gene mutations are recognized as mutations in the 315 th codon of the $k a t G$ gene, which mainly results in Ser315Thr1 and Ser315Thr2 changes. ${ }^{11,14,45}$ The present study revealed that $k a t G$ gene mutation responsible for Ser315Thrl amino acid substitution was observed in $83.3 \%$ of INH-resistant MTB, which is comparable to the reports from Nepal (81.2\%), Pakistan (84\%), Lithuania (85.7\%), and Germany (88.4\%). ${ }^{41,45,47}$ One study conducted in Ethiopia has even shown higher prevalence of $k a t G$ gene mutations (94\%) among INH-resistant MTB. ${ }^{19}$ The same study also reported that $100 \%$ of INH resistance was due to $k a t G$ gene mutations causing amino acid substitutions at the position Ser315Thr1. Another study showed that 8\%-43\% of INH resistance is defined as low-level drug resistance mainly caused by the mutations in the promoter region of inh $A$ gene. ${ }^{46}$ The results of this study also revealed a $16.7 \%$ low-level drug resistance, which is within the range reported by Zhang et al ${ }^{46}$ but higher than that reported by Tessema et $\mathrm{al}^{17}$ from Ethiopia.

\section{Conclusion}

In this study, among the mutations associated with the resistance to RIF and INH, the majority were in codon 531 of the $r p o B$ gene and codon 315 of the $k a t G$ gene. Relatively high prevalence of MDR-TB was observed in the study area, compared to the second round national drug resistance survey among both new and previously treated participants. This situation might threaten efforts of TB control activities and further aggravate development of MDR-TB. So, the study underscores the importance of establishing advanced diagnostic facilities for early detection of MDR-TB, and strengthening of laboratories for TB culture and DST should be promoted in the study area. Previous history of anti-TB treatment, close contact with TB patients, and smoking cigarette were important risk factors for the development of drug resistance. Therefore, it is essential to address the problems of development of DR-TB by establishing good TB control programs (DOTS and DOTS plus). 


\section{Acknowledgments}

We acknowledge Haramaya University Postgraduate Program Directorate Department of Biology, Harar Health Research and Regional Laboratory, and Karamara General Hospital for their unreserved help throughout the research period. We also acknowledge Mr Tewodros Girma and staffs of Harar Health Research and Regional Laboratory, Harar, where the GenoTypeMTBDRplus assay was done. Finally, our gratitude goes to all patients who were willing to participate in the study.

\section{Author contributions}

Mussie Brhane was the primary researcher, who conceived and designed the study, participated in sample collection, performed molecular DST, conducted data analysis, and drafted the manuscript for publication. Ameha Kebede and Yohannes Petros conceived and designed the study, participated in data analysis, and supervised and reviewed the initial and final drafts of the manuscript. All authors read and approved the final manuscript.

\section{Disclosure}

The authors report no conflicts of interest in this work.

\section{References}

1. Varaine F, Kenkens M, Grouzard V. Tuberculosis: Practical Guide to Clinicians, Nurses, Laboratory Technicians and Medical Auxiliaries. 5th ed. France, Paris: Medecins Sans Frontieres. 2010:164.

2. World Health Organization (WHO). Global Tuberculosis Report 2013. WHO/HTM/TB/2013.11. Geneva, Switzerland: WHO.

3. Federal Ministry of Health of Ethiopia. Guidelines for Clinical and Programmatic Management of TB, TB/HIV and Leprosy in Ethiopia. 5th ed. Addis Ababa, Ethiopia: Federal Ministry of Health of Ethiopia; 2013.

4. Gandhi NR, Nunn P, Dheda K, et al. Multi drug-resistant and extensively drug-resistant tuberculosis: a threat to global control of tuberculosis. Lancet. 2010;375:1830-1843.

5. Federal Ministry of Health of Ethiopia. Guidelines on Programmatic Management of Drug Resistance TB in Ethiopia. 2nd Ed. Addis Ababa: Federal Ministry of Health of Ethiopia; 2014.

6. Hillemann D, Rusch-Gerdes S, Richter E. Evaluation of the GenoTypeMTBDRplus assay for rifampin and isoniazid susceptibility testing of Mycobacterium tuberculosis strains and clinical specimens. J Clin Microbiol. 2007;45(8):2635-2640.

7. Steingart KR, Schiller I, Horne DJ, Pai M, Boehme CC, Dendukuri N. $\mathrm{Xpert}^{\mathbb{B}} \mathrm{MTB} / \mathrm{RIF}$ assay for pulmonary tuberculosis and rifampicin resistance in adults. Cochrane Database Syst Rev. 2014;21;(1):CD009593.

8. Woldemeskel D, Abate G, Lakew M, et al. Evaluation of a direct colorimetric assay for rapid detection of rifampicin resistant Mycobacterium tuberculosis. Ethiop J Health Dev. 2005;19(1):51-54.

9. WHO. Molecular Line Probe Assays for Rapid Screening of Patients at Risk of Multidrug Resistant Tuberculosis (MDR-TB): Policy Statement. Geneva: WHO; 2008.

10. Heifets LB, Cangelosi GA. Drug susceptibility testing of Mycobacterium tuberculosis: a neglected problem at the turn of the century. Int J Tuberc Lung Dis. 1999;3(7):564-581.
11. Riccardi G, Pasca MR, Buroni S. Mycobacterium tuberculosis: drug resistance and future perspectives. Future Microbiol. 2009;4(5): 597-614.

12. Alcaide F, Coll P. Advances in rapid diagnosis of tuberculosis disease and anti-tuberculous drug resistance. Enferm Infect Microbiol Clin. 2011;29(Suppl 1):34-40.

13. Zhang Y, Yew WW. Mechanisms of drug resistance in Mycobacterium tuberculosis. Int J Tuberc Lung Dis. 2009;13(11):1320-1330.

14. Vilcheze C, Jacobs WR Jr. The mechanism of isoniazid killing: clarity through the scope of genetics. Annu Rev Microbiol. 2007;61:35-50.

15. Mitike G, Kebede D, Yeneneh H. Prevalence of anti-tuberculosis drug resistance in Harar Tuberculosis Centre, Ethiopia. East Afr Med J. 1997;4(3):158-161.

16. WHO. Guidelines for Programmatic Management of Drug-Resistant TB, 2011 Update. WHO/HTM/TB/2011.6. Geneva, Switzerland: WHO, 2011.

17. Tessema B, Beer J, Emmrich F, Sack U, Rodloff AC. Analysis of gene mutations associated with isoniazid, rifampicin and ethambutol resistance among Mycobacterium tuberculosis isolates from Ethiopia. BMC Infect Dis. 2012;12:37.

18. Barnard M, Parsons L, Miotto P, et al. Molecular Detection of DrugResistance Tuberculosis by Line Probe Assay. Laboratory manual For resource-limited settings. Geneva, Switzerland: FIND; 2012.

19. Hain Lifescience GmbH. Line Probe Assay; GenoTypeMTBDRplus VER 2.0, Instruction for Use, 2012 [Thesis]. Nehren, Germany: Hain Lifescience $\mathrm{GmbH}$.

20. Biadglegne F, Sack U, Rodloff AC. Multidrug-resistant tuberculosis in Ethiopia: efforts to expand diagnostic services, treatment and care. Antimicrob Resist Infect Control. 2014;3:31.

21. Hussein B, Debebe T, Wilder-Smith A, Ameni G. Drug susceptibility test on Mycobacterium tuberculosis isolated from pulmonary tuberculosis in three sites of Ethiopia. Afr J Microbiol Respir. 2017(9):791-796.

22. Agonafir M, Eshetu Lemma E, Woldemeskel D, et al. Phenotypic and genotypic analysis of multidrug-resistant tuberculosis in Ethiopia. Int J Tuberc Lung Dis. 2010;14(10):1259-1265.

23. Abate D, Taye B, Abseno M, Biadgilign S. Epidemiology of antituberculosis drug resistance patterns and trends in tuberculosis referral hospital in Addis Ababa, Ethiopia. BMC Res Notes. 2012;5:462.

24. Esmael A, Ali I, Agonafir M, et al. Drug Resistance Pattern of Mycobacterium tuberculosis in Eastern Amhara Regional State, Ethiopia. J Microb Biochem Technol 2014;6:75-79.

25. Abebe G, Abdissa K, Abdissa A, et al. Relatively low primary d r u g resistant tuberculosis in southwestern Ethiopia. BMC Res Notes. 2012;5:225.

26. Seyoum B, Demissie M, Worku A, Bekele S, Aseffa A. Prevalence and Drug Resistance Patterns of Mycobacterium tuberculosis among new smear positive pulmonary tuberculosis patients in eastern Ethiopia. Tuberc Res Treat. 2014;2014:753492.

27. Ogaro TD, Githui W, Kikuvi G, Okari J, Wangui E, Asiko V. Antituberculosis drug resistance in Nairobi, Kenya. Afr J Health Sci. 2012; 20:21-27.

28. Wright A, Zignol M, Van Deun A, et al. Epidemiology of antituberculosis drug resistance 2002-07: an updated analysis of the global project on anti-tuberculosis drug resistance surveillance. Lancet. 2009;373(9678):1861-1873.

29. Willy U, Ferdinand M, Eduardo V, et al. Primary antimicrobial resistance among Mycobacterium tuberculosis isolates from HIV seropositive and HIV seronegative patients in Dares Salaam Tanzania. BMC Res Notes. 2008;1:58.

30. Chacón L, Laínez M, Rosales E, Mercado M, Caminero J. Evolution in the resistance of Mycobacterium tuberculosis to anti-tuberculosis drugs in Nicaragua. Int J Tub Lung Dis. 2009;13(1):62-67.

31. Dye C. Doomsday postponed? Preventing and reversing epidemics of drug-resistant tuberculosis. Nat Rev Microbiol. 2009;7(1):81-87.

32. Sanchez-Padilla E, Dlamini T, Ascorra A, et al. High prevalence of multidrug-resistant tuberculosis, Swaziland, 2009-2010. Emerg Infect Dis. 2012;18(1):29-37. 
33. Nunes EA, De Capitani E, Coelho ME, et al. Patterns of antituberculosis drug resistance among HIV-infected patients in Maputo, Mozambique, 2002-2003. Intern J Tuberc and Lung Dis. 2005;9(5): 494-500.

34. Sindani I, Fitzpatrick C, Falzon D, et al. Multidrug-resistant tuberculosis, Somalia, 2010-2011. Emerg Infect Dis. 2013;19(3):478-480.

35. Temple B, Ayakaka I, Ogwang S, et al. Rate and amplification of drug resistance among previously-treated patients with tuberculosis in Kampala, Uganda. Clin Infect Dis. 2008;47:1126-1134.

36. Liu Q, Zhu L, Shao Y, et al. Rates and risk factors for drug resistance tuberculosis in northeastern China. BMC Public Health. 2013; 13:1171.

37. Choi JC, Lim SY, Suh GY, et al. Drug resistance rates of Mycobacterium tuberculosis at a private referral center in Korea. J Korean Med Sci. 2007;22(4):677-681.

38. Hirpa S, Medhin G, Girma B, et al. Determinants of multidrug-resistant tuberculosis in patients who underwent first-line treatment in Addis Ababa: a case control study. BMC Public Health 2013;13:782.

39. Berhan A, Berhan Y, Yizengaw D. A meta-analysis of drug resistant tuberculosis in Sub-Saharan Africa: how strongly associated with previous treatment and HIV co-infection? Ethiop J Health Sci. 2013;23(3): 271-282.

40. Kidenya BR, Webster LE, Behan S, et al. Epidemiology and genetic diversity of multidrug-resistant tuberculosis in East Africa. Tuberc (Edinb). 2014;94(1):1-7.
41. Sajduda A, Brzostek A, Popławska M, et al. Molecular characterization of rifampin- and isoniazid-resistant Mycobacterium tuberculosis strains isolated in Poland. J Clin Microbiol. 2004;42(6):2425-2431.

42. Ramaswamy S, Musser J. Molecular genetic basis of antimicrobial agent resistance in Mycobacterium tuberculosis. Tuberc Lung Dis. 1998;79(1):3-29.

43. Zhang Y, Vilcheze C, Jacobs WR. Mechanisms of drug resistance in Mycobacterium tuberculosis. In: Tuberculosis and the Tubercle Bacillus. Cole ST, editor. Washington, DC: ASM Press, Am Society Microbiol; 2005:115-142.

44. Kozhamkulov U, Akhmetova A, Rakhimova S, et al. Molecular characterization of rifampicin- and isoniazid- resistant Mycobacterium tuberculosis strains isolated in Kazakhstan. Japan J Infect Dis. 2011;64(3):253-255.

45. Poudel A, Nakajima C, Fukushima Y, et al. Molecular characterization of multidrug-resistant Mycobacterium tuberculosis isolated in Nepal. Antimicrob Agents Chemother. 2012;56(6):2831-2836.

46. Zhang L, Ye Y, Duo L, et al. Application of genotypeMTBDRplus in rapid detection the Mycobacterium tuberculosis complex as well as its resistance to isoniazid and rifampin in a high volume laboratory in southern China. Mol Biol Rep. 2011;38(3):2185-2192.

47. Bakonyte D, Baranauskaite A, Cicenaite J, Anaida Sosnovskaja A, Stakenas P. Molecular characterization of isoniazid-resistant Mycobacterium tuberculosis clinical isolates in Lithuania. Antimicrob Agents Chemother 2003;47(6):2009-2011
Infection and Drug Resistance

\section{Publish your work in this journal}

Infection and Drug Resistance is an international, peer-reviewed openaccess journal that focuses on the optimal treatment of infection (bacterial, fungal and viral) and the development and institution of preventive strategies to minimize the development and spread of resistance. The journal is specifically concerned with the epidemiology of antibiotic

\section{Dovepress}

resistance and the mechanisms of resistance development and diffusion in both hospitals and the community. The manuscript management system is completely online and includes a very quick and fair peerreview system, which is all easy to use. Visit http://www.dovepress.com/ testimonials.php to read real quotes from published authors. 